\title{
UNDERSTANDING THE RELATIONSHIP BETWEEN PUSH AND PULL TRAVEL MOTIVATIONS AND DESTINATION BRAND IMAGE
}

\author{
Damla Bal ${ }^{1}$ \\ Éva Erdélyi ${ }^{2}$
}

DOI: https://doi.org/10.31410/tmt.2019.155

\begin{abstract}
Branding is the soul of marketing. The destination brand image increases the acknowledgement and feelings of the individual toward the destination and provided tourism services. The specialized and positive brand image of the destination absolutely motivate the individual to awaken the travel desires and to start searching for the internal and external information sources. Owing to the developments in communication and technology in the contemporary era, the individual reaches the information so readily that has let many marketers to realize and focus on the importance of the brand image as it is the picture of the destination in the individual's mind based on what they hear and see from the information sources including social media platforms. Additionally, the picture of the destination in the individual's mind is formed after the visiting experience as well. If that picture of the destination matches with the individual's motivations, the destination has a great power in the evaluation stage of the decision process of the individual. At this point, understanding the travel motivations of the individual has a substantial role in building a destination brand image. In this study, the authors aim to develop a brand image model that will trigger the individual to take travel decision and maximize the value match between the projected image and the perceived image of the destination through linking the cognitive, affective, unique image components with the push and pull travel motivations. Recommendations will be offered how a destination brand image should be built regarding the destination brand image model of the study. With that model, it is expected to guide the destination marketing organisations and the marketing managers in terms of building brand a destination brand image.
\end{abstract}

Keywords: Brand Image Model, Destination Image, Travel Motivations.

\section{INTRODUCTION}

$\mathrm{D}$ estination branding is one of the important tools that the destination marketing managers build a destination brand in order to differentiate the destination from its competitors; gain competitive advantage; attract more visitors, and investment opportunities to the region. Through branding, firstly it is aimed to make the individuals aware of the destination and then to build the desirable connotations for that destination. The main goal of destination branding is to create a destination image that will positively affect the decision process stages of the individuals. From the individual's point of view, the decision process of the destination requires subjective judgement rather than objective measurements as that destination cannot be experienced prior to travel. Therefore, the destination image that the individuals create in their mind based on the limited information plays a significant role in choosing the destination.

Destination branding covers all marketing activities carried out to create a destination image that will trigger the travel desires of the individual. Afterwards, the destination image needs to be as powerful as in order that the individual who recognize the need of travel should start taking action

\footnotetext{
$1 \quad$ Budapest Business School - University of Applied Sciences, H - 1054 Budapest, Alkotmány utca 9-11
}

2 Budapest Business School - University of Applied Sciences, H - 1054 Budapest, Alkotmány utca 9-11 
to follow through the desires. In other words, creating a strong and positive destination image in the mind of the individual constitutes the main purpose of destination branding. Therefore, in order for the destination branding process to succeed, it is substantial to understand the structure of the destination image; its formation process; and the factors affecting the destination image.

In this study, destination brand image, its components and travel motivations will be discussed through secondary research in order to grasp the essence of the topics, that will help to develop a brand image model of this study. The brand image model is built in order to increase the value match between the projected image and the perceived image of the destination based on the cognitive image composed of pull motivations, the affective image composed of push and pull motivations and the unique image composed of push and pull motivations.

\subsection{Literature Review}

Destination image researches are considered to be the precursor to successful destination marketing strategies. Discovering visitors' differences in perceptions, images and motivations toward a destination is essential to comprehend and predict tourism demand and its impact on the tourism location. Indeed, this understanding of destination image and visitors' perceptions is critical to a destination and provides the basis for more effective and efficient future strategic planning of the destination (Di Marino, 2008, p. 1). The perceived destination image, formed by the combination of visitor expectations, personal interpretation of the travel experience and the identity characteristics of the visitor, influences the visitor's decision to choose destination and level of satisfaction. At the decision process, the destination with the favourite image is more likely to be chosen by visitors (Komppula and Laukkanen, 2016, p. 45).

The destination image is the sum of a visitor's impressions of a particular place, or the visitor's general perception of that place. Destination image is more about the perception of the relationship between the individual and the destination than the objective perception of the destination because the visitors' individual interpretations of reality are personal fictions. Crompton (1979) and Reilly (1990) see the image in terms of a picture in the mind; they suggest that destination image is the sum of all those emotional qualities like experiences, beliefs, ideas, recollections and impressions that a person has of a destination (Di Marino, 2008, p.2). Therefore, destination image is unique and the factors affecting image formation are very diverse and the process of formation is complex (Jenkins, 1999, p. 2). Individuals who recognize their desire for travelling benefits from many internal and external sources. Those information sources are promotional literature (travel brochures, posters), the opinions of other experienced visitors (family and friends, travel agents) and the general media (newspapers, magazines, television, books, movies); additionally, the destination image will be affected and modified regarding the first visiting experience (Echtner and Ritchie, 2003, p. 38). Considering the developments in the communication sources in the contemporary era, social media platforms have a great influence on the travel decisions of individuals; for this reason, social media platforms should be taken into consideration regarding the external information sources during the formation of image process. Basically, individuals create images in their mind through the available information of the destinations from various sources over time; and that information become a mental construct which is noteworthy to individuals (Komppula and Laukkanen, 2016, p. 45).

Due to its ambiguous, subjective and abstract features, destination image is difficult to define; besides, it is composed of numerous components (Fakeye and Crompton, 1991, p. 10). In general, 
while many studies agree that the destination image is a general impression and multidimensional, there is no consensus on what dimensions make up this general impression. Baloglu and McCleary (1999) state that considering the rationality and sensuality of individuals destinations image is developed and consists of a combination of two basic dimensions; cognitive and affective (Kim and Chen, 2015, p. 2). From another point of view, Gartner (1994) suggests that the destination image is composed of three dimensions which are distinct but hierarchically related; cognitive, affective and behavioural (p. 193). However, Echtner and Ritchie (2003) suggest that destination image components should include holistic and unique images addition to individual destination attributes (p. 40).

The cognitive image associated with the characteristics of destination, which is developed in an intellectual way. "The cognitive component may be viewed as the sum of beliefs and attitudes of an object leading to some internally accepted picture of its attributes. The number of external stimuli received about an object is instrumental in forming a cognitive image" (Gartner, 1994, p. 193). Ultimately, the tourism consumer must have at least a little knowledge in order for the image of a destination to be formed. Many of the destination image studies focus on the physical, concrete characteristics of the destination, analysing the cognitive perceptions of consumers. The image of the destination should be examined on the basis of the characteristics and attractiveness of its resources, which leads the tourist towards visiting that destination. When the studies of destination image are examined, many attributions such as climate, accommodation, shopping opportunities, landscape, night life, safety, transportation facilities are commonly used; whereas, some attributions such as originality, social interaction, service quality appear less in the research topics. However, it is observed that the list of attributions varies according to the characteristics of the destination, and the purpose of research.

The affective image depends on the visitors' feelings towards the destination. Affect stands for an individual's feelings toward an object, that will be favourable, unfavourable or neutral (Fishbein, cited in Pike and Ryan, 2004, p. 5). According to Gartner (1994), the affective component relating the value that individuals attribute to the destination in line with their motives becomes operational when the evaluation stage of decision process begins (Gartner, 1994, p. 196). Individuals make affective assessments after hearing about destinations therefore the cognitive image has a significant impact on the affective image, and that cognitive image precedes affective elements. In tourism destination image studies, it has been observed that the affective component, which was often neglected, has been taken into account in recent years. Pike (2002) analyses 142 destination image studies published during the period of 1973-2000 that only six of them show an explicit interest in affective images (Pike and Ryan, 2004, p. 6).

The conative image component is analogous to behaviour because it is the action component that after all internal and external information is processed, a decision is made. The conative component's relationship to the other components is direct and depends on the images developed during the cognitive stage and evaluated during the affective stage. (Gartner, 1994, p. 196). "Conation may be considered as the likelihood of visiting a destination within a certain time period” (Pike and Ryan, 2004, p. 7).

The holistic image or general image is composed of general impressions about the destination (Echtner and Ritchie, 2003, p. 43). Um and Crompton (1990) also state that the image of the destination consists of holistic impressions of visitors. "The image of a place as a pleasure travel destination is a gestalt. It is a holistic construct which, to a greater or lesser extent, is derived from attitudes towards the destination's perceived tourism attributes" (Um and Crompton, 1990, p. 432). 
The unique image consists of unique attributes which should distinguish the destination from its competitors (Echtner and Ritchie, 2003, p. 43). Sometimes, it is not enough to choose a destination that is among the various destinations that offer similar features such as quality accommodation or natural landscapes. Therefore, in order for the destination to be the final decision, it must be unique and different from the alternatives that the consumer evaluates. Unique functional attributes can be the icons and special events, such as the Sydney Harbour Bridge or the Glastonbury music festival (Jenkins, 1999, p. 5).

Besides the destination brand image, it is important to examine travel motivation, to highlight the most important reasons that lead tourists to travel, and to identify the characteristics that attract tourists to certain destinations. Motivation is described as a state of necessity which pushes the individual to act in order to reach a certain level of satisfaction; and also, it is a key factor affecting the decision process of possible visitors (Beerli-Palacio and Martín-Santana, 2017).

Dann (1997) introduces the push and pull motivations theory that is widely accepted by the authors; "push factors can, at the most basic level, be explained as intrinsic factors or internal drives that urge individuals to travel" (Yousaf and Amin, 2018, p. 202). The pull motivations are the attributes of the destinations' overall attractiveness (such as beautiful landscapes, cultural attractions, beaches, historical sites, etc.); accordingly, the push and pull motivations work together that the destination attributes can trigger the internal drives (Cassidy, 2005, p. 6).

\subsection{Destination Image Model of the Study}

The image of destination can be defined as follows; if the mind of the person is considered as a canvas, all kinds of push and pull travel motivations that influence the visitor can be a touch and a point to that canvas. The projected destination image which the destination marketers build and the perceived destination image which is formed by the combination of visitor expectations, personal interpretation of the travel experience and the characteristics of visitor are very important for strategic destination marketing planning as both impact the individual's decision process and the level of satisfaction. Destination image plays a substantial role in the potential visitor's travel behaviours and decisions and suggest that destinations with a strong, positive image are probably more considered and selected during travel decision process.

The destination image representing all the individual's knowledge about the destination and one's feelings towards the destination is a general impression of the destination. In other words, the image of destination encompasses all connotations in the form of all kinds of thoughts, beliefs, feelings and attitudes that destination evokes and associates with the individual. However, the destination image is more related to the perception of the relationship between the individual and the destination than to the objective perception of the destination as the visitor's individual interpretation of reality is a personal fiction.

From the individual's point of view, travel decisions require subjective judgment rather than objective measurements, as the tourism product cannot be experienced prior to travel. Yet potential visitors have often secondary knowledge about a destination as they have not visited the destination before. Therefore, the projected destination image in the visitor' mind about that destination is very effective in the decision process; and the perceived image is very substantial as the experienced visitors can impact the potential visitors' decisions with their opinions and sharing on the social media platforms. 
For destination marketers, destination image is important because its projected and perceived images affect the behaviours, attitudes and tendencies of the visitors, and the main competition takes place between the competitive destinations in order to gain a positive place in the mind of visitors. In this context, the value match between the perceived destination image of the visitors and the projected destination brand image during the branding process indicates that realistic and consistent expectations are created and that these expectations are met.

The individual compares the information $\mathrm{s} / \mathrm{he}$ faces under the destination brand with the typical images $\mathrm{s} / \mathrm{he}$ has in her/his minds. Potential visitor can adapt the information $\mathrm{s} /$ he faces with a particular destination by matching it with the existing destination image $\mathrm{s} /$ he has. The destination image in the mind of the individual becomes more realistic, complex and differentiated after visiting the destination. If the visitor thinks that there is a value match between what $\mathrm{s} / \mathrm{he}$ expect and what $\mathrm{s} /$ he finds, it can be said that the destination has a strong image.

Moreover, the travel motivations play a significant role in the stages of decision process as the travel motivations are the main factor which persuades the individual to take travel decision. Pull motivations relating the destination attributes push the individual to act in a certain way and trigger off the individual's inner motivations so called push motivations. If an individual prefers to have romantic memories, s/he will look for destinations which has a romantic image. On the other hand, the romantic image of the destination can also provoke one's push motivations that the individual starts considering the trip to that destination. Additionally, for the individuals who like being physically active prefer destinations which provide an opportunity to do a certain type of an activity the cognitive image of the destination plays a substantial role as it is related to the attractiveness of the destination. Accordingly, one can consider the push and pull travel motivations as an integral part of destination image components during the process of building a destination brand image.

The image formation in the visitors' mind is based on the information sources and push and pull travel motivations; however, elaboration of this process will be useful for a better understanding of the subject. It is seen that there is a need for a model which combines the push and pull travel motivations with destination image components that will lead the individual to take travel decision and increase the value match between the projected image and the perceived image. That is why, the authors develop a triangular prism destination brand image model that will link the push and pull motivations with three image components which are cognitive image, affective image and unique image of the destination in order to make the destination more attractive and to ensure the value match.

The model is designed in the form of a triangular prism created by using Corel Draw and Adobe Photoshop programs. The main idea behind using the triangular prism as a model is to show that all these elements depend one another that any communication mistake or misunderstanding can lead to a negative destination image.

The two triangular bases are composed of the projected image and the perceived image, that stands for the effect of puzzle. It is not a secret anymore that in the contemporary the individual can easily reach the information; furthermore, the impact of social media platforms is undeniable. The individuals who have not visited the destination are increasingly affected by internal and external information sources. Those information sources are ways of introducing the projected image of the destination. Furthermore, the opinions of experienced visitors are highly important in the travel decisions of the individuals. That is why, the destination should meet the 
expectations of the visitors. At this point, it is important to understand the push and pull travel motivations of the tourist in order that the destination attributes can be improved based on that importance; and, the destination brand image should include the important travel motivations as well. If the destination image provokes the push and pull travel motivations of the individual, the possibility of the visit intention increases and s/he can take the travel decision. When the individual visits the destination, if the projected image is realistic and the destination matches with her/his travel motivations, s/he identifies herself/himself with the destination. In that way, a strong value match will be generated between the projected image and the perceived image. Thanks to this value match, the revisit intention of the experienced visitors will be positively affected and also, they can recommend the destination to the other possible visitors; share positive posts on social media; personalize the website of the destination with positive comments as well. Accordingly, the value match between the projected image and the perceived image will positively affect the stages of decision process of the individual. The projected image should be strengthened by three lateral faces which are the combinations of three destination image components with push and pull motivations. As previously discussed, the importance of the push and pull motivations influence the decisions of the individuals that is why the three-image components should be constructed considering the push and pull motivations.

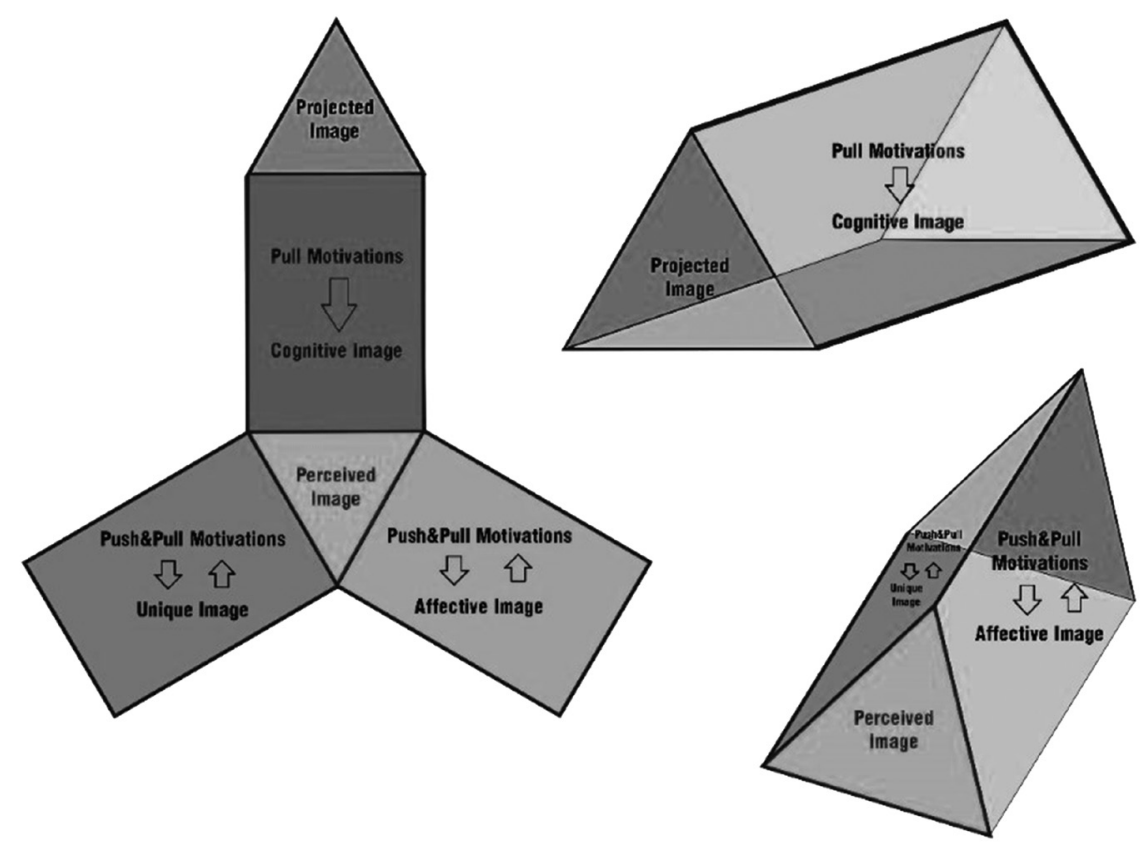

Figure 1. The triangular prism of destination image

Source: Own source

There is no precise model regarding the destination image components; however, five destination image components (cognitive, holistic, unique, affective, conative) are given in the literature review. In this triangular prism of destination image model, three components (cognitive, affective, unique) are decided to be used because the holistic image represents overall image that one can call it as the general destination image including three mentioned components. The conative image is described as the likelihood of travel to the destination; therefore, one can see it as a purchase stage of the decision process.

The cognitive image is set as a base of three lateral faces, because it motives the possible visitors of the destination to follow their travel desires and creates the unique image as well. In other 
words, the cognitive image pushes the visitors to take travel decisions. In the model, pull motivations which contribute to the attractiveness of the destinations constitute the cognitive image. Therefore, when building a destination image, the marketers should emphasize the certain destination attributes which are the pull motivations of the individuals. Besides, the affective image comprises of push and pull motivations that any push motivation factor can also relates to the affective image; and, any certain type of activity related to the attributes of the destination can develop strong emotional connections with the visitor. Also, the unique image consists of push and pull motivations that any landscape, cycle road, restaurant, culture, etc. can be very special and unique for the visitors; and also, any place can be very unique with the sentimental moments or memories or experiences.

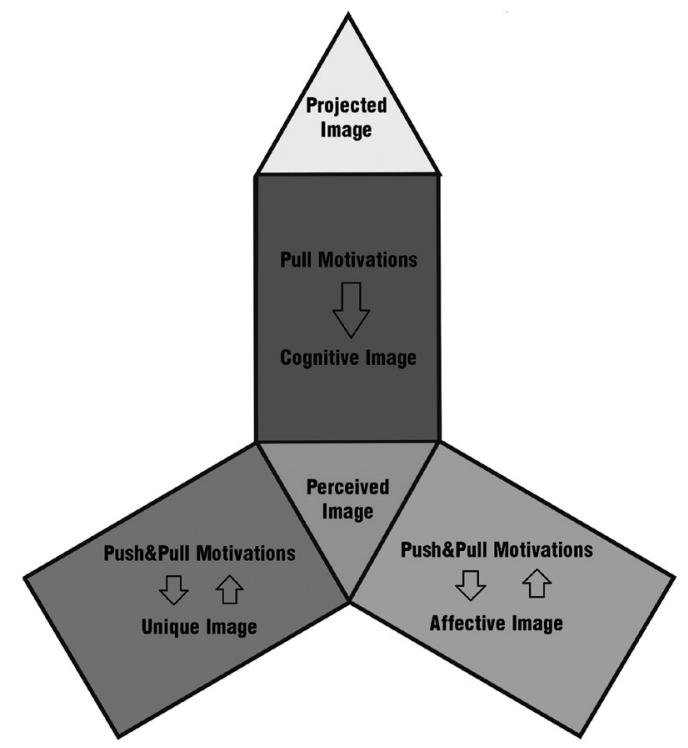

Figure 2. Surface area of the triangular prism of destination image

Source: Own source

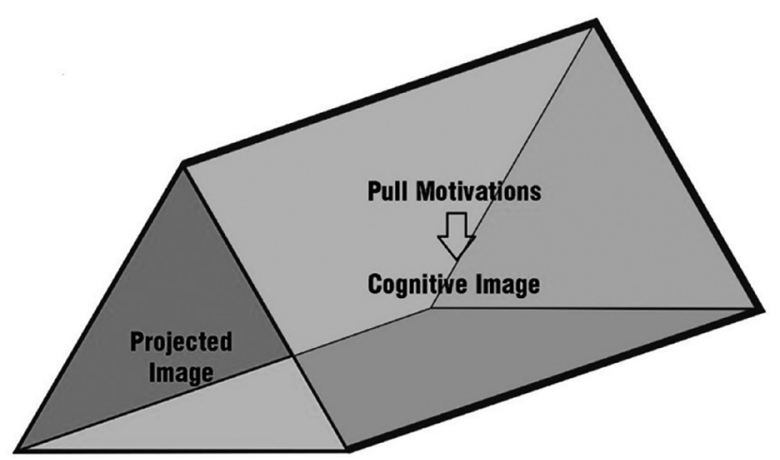

Figure 3. Base aspect of the triangular prism of destination image

Source: Own source

As it is shown in the figure 3, the base of the model is the cognitive image composed of the pull motivations. The figure 4 shows the outlook of the triangular prism of destination image that one can see the other two lateral faces; the affective and unique images which should be constructed considering the push and pull travel motivations of the target group. The triangular bases have the same significance with the other. However, in the model it is preferred that the perceived image is seen in the front part of the triangular prism, because the perceived image is last one which stays in the visitors' mind even though there is a circle between the projected image and the perceived image. 


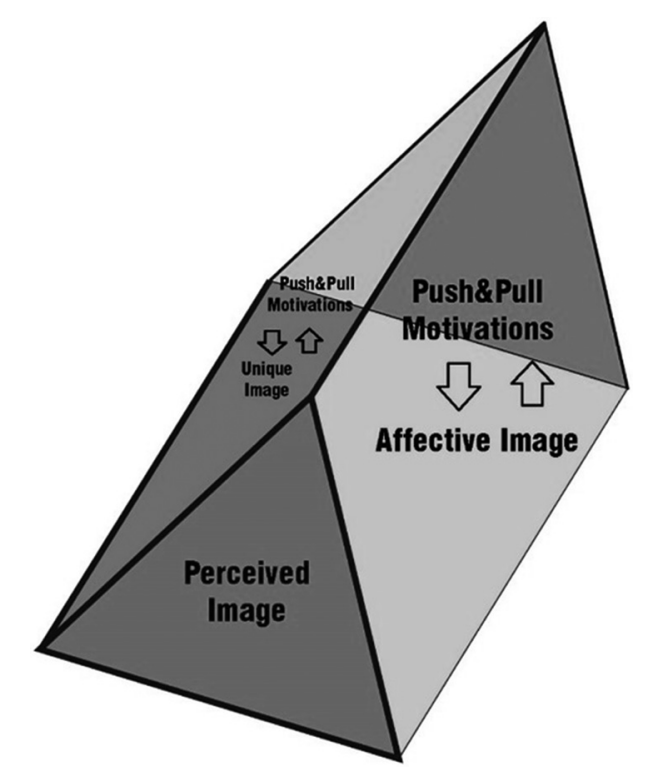

Figure 4. Outlook of the triangular prism of destination image

Source: Own source

The cognitive, affective, unique images should be enough persuasive to affect the travel motivations of the individuals. That is why, when building a destination image, the travel motivations of the individuals (target group) should be examined firstly then the three image components must be projected taking into consideration the most important travel motivations of the individuals in order that those images provoke the travel motivations of the individuals that also provokes the travel decisions of the individuals.

Furthermore, it is important to maximize the value match between the projected image and perceived image in the light of the brand image model of the study. In order to increase the level of value match, a realistic picture should be created. The local stakeholders, governors, private investors should also focus on improving the attributes of the destination which are important motivation sources for the individuals.

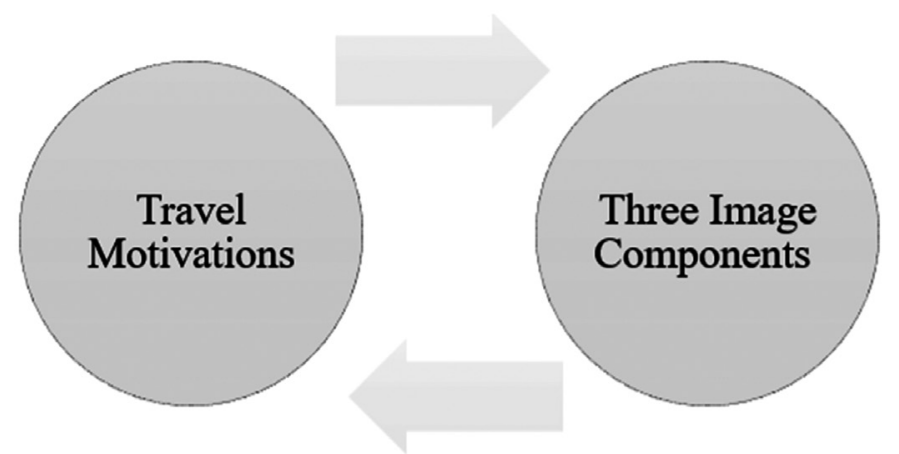

Figure 5. The relationship between the travel motivations and three image components

Source: Own Source

\subsection{Case Study}

In this case study, the authors aim to build the brand image of a rural development project according to the destination brand image model. It is clear that the push and pull travel motivations have a major impact on the travel decisions of the individuals. However, the new developments 
in the destinations might not be the most important pull motivations of the individuals. At this point it is important to trigger the push motivations of the individuals by the help of the attractiveness of the new developments. That is why the authors chose a rural development project which is still ongoing in order to demonstrate an example of how to construct the destination brand image regarding the new developments.

As many countries, Hungary focuses on activating the potential of rural regions in order to increase the competitiveness of the destinations. The Minister of Rural Development of Hungary highlighted the significance of Lake Tisza Complex Project, which intends to attract more tourists to the region during his visit to Lake Tisza Expo in May 2014. It is still progressing. The Lake Tisza Complex Projects is composed of several sub projects which are as follows: increasing the number of marinas along the river Tisza; import of 20 canal boats for holiday rentals; reconstruction of the cycle and walking paths; fishing pass which is an ecological project to restore the fish migration roads in Danube; cleaning of the Tisza lake and river which is an ecological project.

The brand image of the holiday boat rental will be focused in this part. There will be 12 mooring points in the river Tisza including 2 marinas in Lake Tisza. The figure 6 shows those mooring points in the region. The new boats will be located at Kisköre and Tokaj marinas. Furthermore, there will be no required license and previous boating experience in order to rent those canal boat.

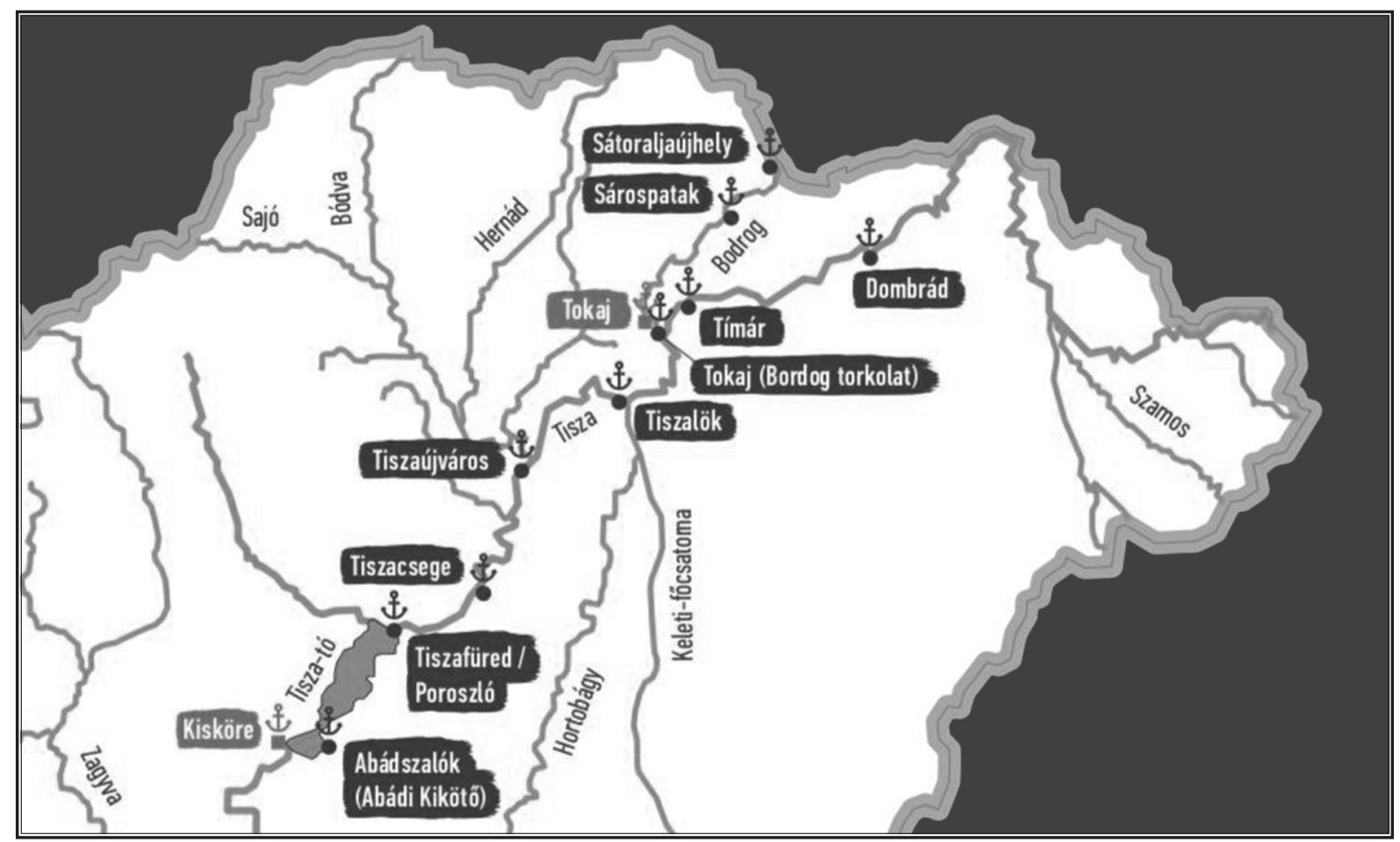

Figure 6. Map of the developing marinas in the region

Source: Nicols Company, 2019

The understanding of push motivations of the domestic tourists in Hungary plays an important role in building the brand image of the concept of holiday boat rental as it is a new attraction. The target group constitutes domestic tourists because at the beginning of introducing a new development in a particular rural destination domestic tourists' demands are much higher comparing the international tourists. In order to examine the push motivations of the domestic tourists in Hungary an online questionnaire used as a qualitative method. 
The questionnaire consists of three main parts. The first part contains 8 multiple choice questions about the demographic characteristics of the respondents. The questions are formed to understand their gender, age, education, marital status, employed status, household income status; and to determine which city they live in, and how many children/grandchildren they have under 18 if they have any. The second part composed of 5 questions is associated with the respondents' travel behaviours. The aim of the questions is to understand how often they travel in general and to countryside; whether they have any cottage in the countryside or not; how long their countryside trips are; who their travel mates are. The third part of the questionnaire consists of 9 questions about the push travel motivations of the respondents. The questions are also developed in terms of the literature review. The respondents are asked to rate their push motivations on a 5 -Likert scale that how important these 9 factors are as $1=$ not at all important, $2=$ less important, $3=$ neutral, $4=$ important, $5=$ very important.

At the final stage, a pilot application is made to test the intelligibility of the survey form by sending 5 people who has different backgrounds. The survey form was shared on the social platforms between $25^{\text {th }}$ of October and $5^{\text {th }}$ of November, 2019 after giving its final shape in terms of design and verbal expression. The language of the questionnaire is English that is an important limitation of the study.

123 valid answers are gathered and results are analysed using different statistical methods. Based on results major characteristics of the respondents are demonstrated in the following lines. The of woman respondents are 49,59\% of the sample group and man respondents represent $50,41 \%$. Most of the respondents are $25-34$ old years old and consist of 54,47\% of the total respondents. 57,72\% of the respondents live in Budapest. 39,84\% the respondents have bachelor's degree while $36,59 \%$ of the respondents have master degree. $42,28 \%$ of the respondents are single, and $35,77 \%$ of the respondents have a relationship. $21,95 \%$ of the respondents are married. $86,18 \%$ of the respondent do not have any child. $43,90 \%$ of the respondents are fulltime employed. $65,04 \%$ of the respondents have medium income level.

The findings of the respondents' travel behaviours are summarized in the figure 7.

$33.33 \%$ of the sample group travel monthly, and $53,66 \%$ of the respondents travel a few times a year. On the other hand, $26,83 \%$ of the respondents travel to the countryside monthly, $43,09 \%$ of respondents travel to the countryside a few times a year. $78,05 \%$ of the respondents do not have any cottage in the countryside.

\begin{tabular}{|l|c|c|}
\hline Frequency of travelling & Number of Respondents & $\mathbf{\%}$ \\
\hline Weekly & 5 & $4,07 \%$ \\
\hline Monthly & 41 & $33,33 \%$ \\
\hline A few times a year & 66 & $53,66 \%$ \\
\hline Occasionally & 11 & $8,94 \%$ \\
\hline Frequency of countryside trips & Number of Respondents & $\mathbf{\%}$ \\
\hline Weekly & 8 & $6,50 \%$ \\
\hline Monthly & 33 & $26,83 \%$ \\
\hline A few times a year & 53 & $43,09 \%$ \\
\hline Occasionally & 29 & $23,58 \%$ \\
\hline Having a cottage in the countryside & Number of Respondents & $\mathbf{\%}$ \\
\hline Yes & 27 & $21,95 \%$ \\
\hline No & 96 & $78,05 \%$ \\
\hline
\end{tabular}

Figure 7. Travel behaviour of the respondents

Source: Own Source 


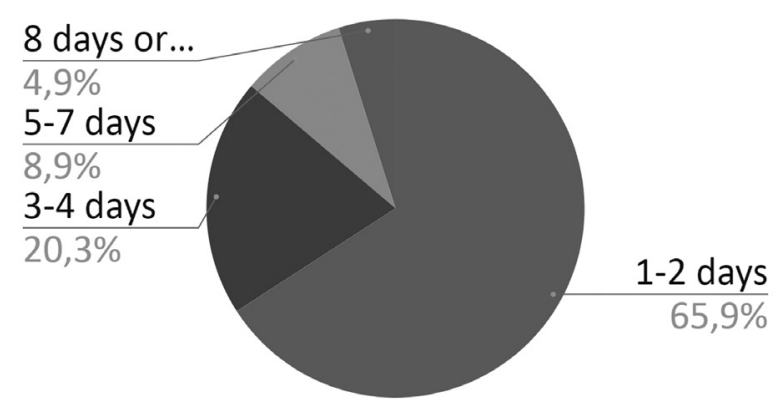

Figure 8. Length of stay of the respondents

Source: Own Source

Additionally, $65,9 \%$ of the respondents prefer 1-2 days countryside trips; however, $20,3 \%$ of the respondents prefer 3-4 days countryside trips. It is observed that there is not too much demand for long countryside trips as $8,9 \%$ of the respondents do 5-7 days trips and $4,9 \%$ of the respondents do 8 days or longer trips.

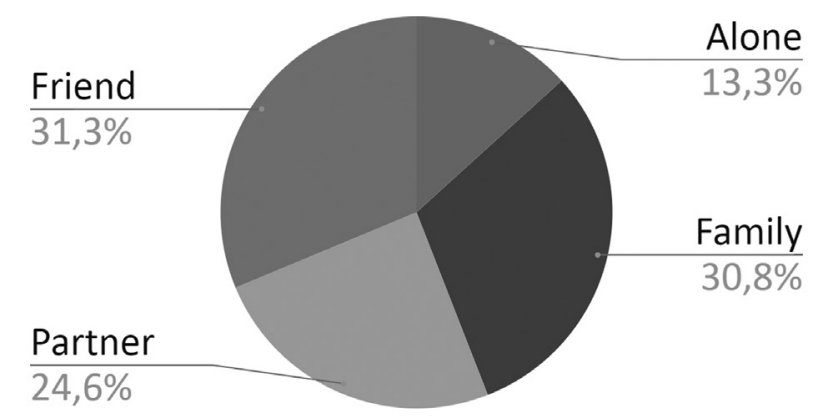

Figure 9. Travel mates of the respondents Source: Own Source

$31,3 \%$ of the respondents prefer travelling with friends, $30,8 \%$ of the respondents' travel mates are friends. Additionally, $24,6 \%$ of the respondents travel with their partners. $13,3 \%$ of the respondents constitutes solo travellers.

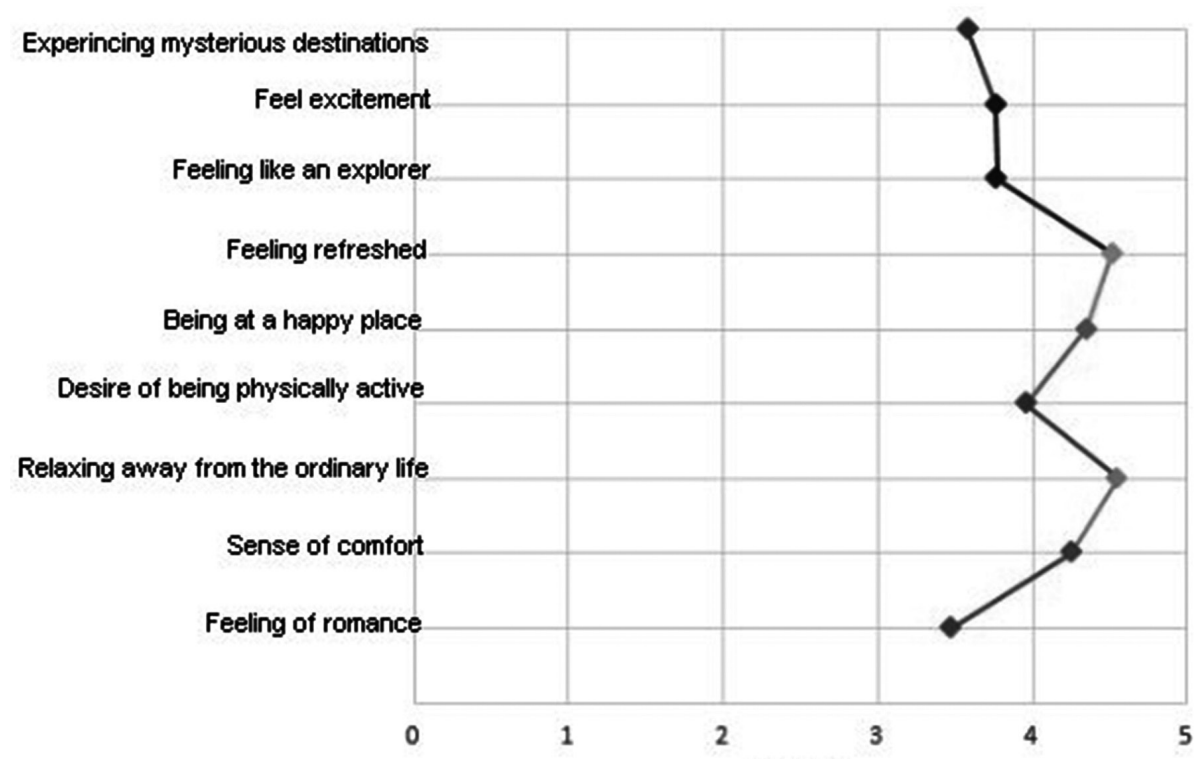

Figure 10. Mean calculations of the push motivations

Source: Own Source 
Regarding the push motivations of the sample group, it is seen that relaxing away from the ordinary life is the most encouraging push motivation that for $\% 67,5$ of respondents mark it as very important. Additionally, feeling refreshed is very close to the relaxing away from the ordinary life. Consequently, it can be said that in the contemporary technology era, people are generally looking forward to escaping from the daily routine and its stress.

The other push motivations which are important are being at a happy place and sense of comfort. Addition to this, desire of being physically active, feeling like an explorer, feeling excitement about the destination, and feeling romance have relatively importance.

\begin{tabular}{|c|c|c|c|}
\hline Push Motivations & Mean & $\begin{array}{c}\text { Percent of } \\
\text { respondents voted } \\
\text { for ' } 5 \text { ' }\end{array}$ & $\begin{array}{c}\text { Percent of } \\
\text { respondents voted } \\
\text { for ' } 4 \text { ' }\end{array}$ \\
\hline Relaxing away from the ordinary life & 4,5528 & $\% 67,5$ & $\% 22$ \\
\hline Feeling refreshed & 4,5203 & $\% 64,2$ & $\% 26$ \\
\hline Being at a happy place & 4,3496 & $\% 52$ & $\% 34,1$ \\
\hline Sense of comfort & 4,252 & $\% 46,3$ & $\% 37,4$ \\
\hline Desire of being physically active & 3,9593 & $\% 35$ & $\% 35$ \\
\hline Feeling like an explorer & 3,7724 & $\% 25,9$ & $\% 29,3$ \\
\hline Feeling excitement about the destination & 3,7642 & $\% 29,3$ & $\% 32,5$ \\
\hline Experiencing mysterious destinations & 3,5854 & $\% 22,8$ & $\% 31,7$ \\
\hline Feeling of romance & 3,4715 & $\% 17,9$ & $\% 34,1$ \\
\hline
\end{tabular}

Figure 11. Mean calculations of the push motivations-2

\section{Source: Own Source}

It can be concluded that for domestic tourists in Hungary relaxing away from the ordinary life, feeling refreshed, being at a happy place and sense of comfort are triggering factors. Therefore, those factors must show up in the brand image of the holiday boat rental in the region. The commercials regarding this project should spread that the canal boat for holiday helps to escape from daily life and provides the feeling of refreshed. Additionally, the commercials must show a happy atmosphere with family, friends and partners; give the sense of comfort. The canal boats and the development of marinas will bring a new soul to there. That is why the projected image of the holiday boat rental must be very positive to impact the decisions of the individuals through effecting the push motivations of them. On the other hand, the expectations of the individuals what are created by the commercials should be met in order to maximize the value match between the projected image and the perceived image.

\section{CONCLUSION}

Today, competition is not only between products or companies, but also between destinations. When one looks at this framework, destinations which want to gain an advantage in competition need to determine the characteristics that will enable them to be a brand and go on the way to benefit from them. In fact, every destination is a brand, because each destination has distinctive features and differences from another destination. However, every destination brand does not have the same value. Some destination brands are considered more valuable by their target visitors, while others are seen as less valuable. At this point, it is important to understand how those destination brands are perceived from the individuals. That is why, it is also important to project a destination brand image which has a superior place in the individuals' mind and improve the tourism services to meet the expectations of the individuals in order to be a favourable destination at the decision process of the individuals. 
Destination brand image is the sum of one's impressions, feelings, thoughts, beliefs and connotations regarding the destination. Destination brand image can also be defined as the picture that individuals creates in their mind according to what they perceive in terms of the destination or as the sum of what individuals understand from the destination. Brand image is the result of the individuals' impressions about a brand from various sources. A destination brand image is a collection of often controllable perceptions of that destination, such as its strengths and weaknesses, its positive and negative sides.

Like company brand images, destination brand images must be managed as well. Destination brand images that are not properly managed will change or be harmed in an unintended direction. Due to improved communication opportunities, negative information about the destination can be spread over a wide area in a very short time. The brand image of the destination, which has been created in a long time and with large investments, can be badly damaged by the negative impacts like domino stones. Therefore, it is important to maintain the destination brand image as much as creating a positive image.

For a successful and positive destination image, the right strategies should be chosen. A strong destination brand image can differentiate itself from its competitors, minimize perceived risk of the travel decision by the possible individuals, and emerge as a high quality in the individuals' perspective. The destination brand image planned by the marketers should definitely match the perceived image of the destination by the tourists as this value match will positively affect their revisit intention and the possible tourists' travel decisions.

If a destination brand image contains certain assets that the individuals is able to integrate with their own motivations, the priority of that destination will be higher and the destination can be easily recognized by the individuals because the individuals' motivations will be triggered by the destination image. In line with these explanations, it is clear that the commitment and preference criteria of the individuals will be positively affected by the destination brand image thanks to the correlation of their motivations and the destination image.

When individuals decide where to travel, they evaluate the information collected through the internal and external information sources. One of the evaluation steps is the comparison of self-image and perceived brand image. Individuals tend to choose brands whose perceived image provoked by their motivations. Changes in the perceived brand image can lead to changes in brand preferences. An important consideration is that the impact of the change in image characteristics should be kept in mind when creating new marketing strategies.

This study develops a brand image model which is called as triangular prism of destination image in order to push the individuals to travel the destination and to maximize the value match between the projected image and the perceived image. The triangular bases consist of the projected image and the perceived image, while three lateral faces consist of the cognitive image composed of the pull motivations, the affective image composed of push and pull motivations, the unique image composed of also push and pull motivation. The model suggest that the cognitive image need to be formed by the important pull motivations of the tourists; the affective image and the unique image should be formed based on the important push and pull motivations. In other words, the cognitive image should be enough strong to push the tourists to take travel decisions. All these elements create a complete triangle prism and any quake among them will lead fail of the triangular prism. 
The destination image built based on the push and pull travel motivations brings along the recognition of travel desire of the individuals and play an effective role in the evaluation of the destinations if the individuals identify themselves with the projected image of the destination. Furthermore, the destination image which triggers the travel motivations of the individual leads them to take travel decisions. If the destination meets the expectations (motivations) of the individuals, the value match will be created between the projected image and the perceived image. There is a circle also between these steps mentioned. If there is a value match between the projected image and the perceived image, the revisit intention will be positively affected; and the satisfied visitors' recommendations will be also an information source that will affect other possible visitors' decisions. In this way, the value match will result in another individuals' recognitions in terms of their travel wishes.

For the future researches, the authors aim to improve the triangular prism of destination image model through multi-case study that will focus several destinations that will be critically chosen. Additionally, the impact of social media on the destination image will be measured by conducting a case study. The authors aim to generate social media strategies for the destinations to have a competitive advantage and positive brand image.

\section{REFERENCES}

Beerli-Palacio, A., \& Martín-Santana, J. (2017). How Does Confirmation of Motivations Influence on the Pre- and Post-visit Change of Image of a Destination? European Journal of Management and Business Economics; 26(2), 238-251.

Cassidy, F. (2005). What Motivates Sports Event Tourists? A Synthesis of Three Disciplines. Retrieved from https://eprints.usq.edu.au/845/1/Cassidy_Sept_5_2005_version.pdf

Di Marino, E. (2005). The Strategic Dimension of Destination Image. An Analysis of the French Riviera Image from the Italian Tourists' Perceptions. Retrieved from https://www.esade.edu/cedit/ pdfs/papers/pdf10.pdf

Echtner, M. Charlotte, \& Ritchie, J.R. (2003). The Meaning and Measurement of Destination Image. The Journal of Tourism Studies; 14(1), 37-48.

Fakeye, P., \& Crompton, J. (1991). Image Differences Between Prospective, First-Time, and Repeat Visitors to the Lower Rio Grande Valley. Journal of Travel Research; 30(2), 10-16.

Gartner, W. (1994). Image Formation Process. Journal of Travel \& Tourism Marketing; 2(2-3), 191-216.

Jenkins, O. (1999). Understanding and Measuring Tourist Destination Images. International Journal of Tourism Research; 1, 1-15.

Kim, H., \& Chen, J. (2015). Destination image formation process: A holistic model. Journal of Vacation Marketing; 1-13.

Komppula, R., \& Laukkanen, T. (2016). Comparing Perceived Images with Projected Images- A case study on Finnish ski destinations. European Journal of Tourism Research; 12, 41-54.

Pike, S., \& Ryan, C. (2004). Destination Positioning Analysis through a Comparison of Cognitive, Affective, and Conative Perceptions. Journal of Travel Research, 42(4), 1-36.

Twenty Canal Boats to Be Built for Rental from Kisköre and Tokaj in 2020. (2019, January 11). Retrieved from https://www.boat-renting-nicols.co.uk/latest-news/nicols-wins-major-contract-inhungary

Um, Scoho, \& Crompton, John. (1990). Attitude Determinants in Tourism Destination Choice. Annals of Tourism Research; 17, 432-448.

Yousaf, A., Amin, I., \& Santos, J. (2018). Tourist's Motivations to Travel: A Theoretical Perspective on the Existing Literature. Tourism and Hospitality Management; 24(1), 1-15. 